Salud y Servicios sociales

\title{
Polimorfismos genéticos CYP2C9 y VKORC1-1639 implicados en la farmacocinética y farmacodinámica de warfarina en población latinoamericana
}

\author{
CYP2C9 and VKORC1-1639 genetic polymorphisms \\ involved in warfarin pharmacogenetics and \\ pharmacodynamics in Latin American population
}

\author{
Negaresh, Sara; Silva Arrechavala, José René; Corriols, Marianela
}

\author{
Sara Negaresh \\ snegaresh@unan.edu.ni \\ Universidad Nacional Autónoma de Nicaragua, \\ Managua , Nicaragua \\ José René Silva Arrechavala \\ rsilva@unan.edu.ni \\ Universidad Nacional Autónoma de Nicaragua, \\ Managua , Nicaragua \\ Marianela Corriols \\ marianelacorriols@gmail.com \\ Universidad Nacional Autónoma de Nicaragua, \\ Managua , Nicaragua
}

Revista Torreón Universitario

Universidad Nacional Autónoma de Nicaragua-Managua,

Nicaragua

ISSN: $2410-5708$

ISSN-e: 2313-7215

Periodicidad: Cuatrimestral

vol. 10, núm. 27, 2021

revis.torreon.faremc@unan.edu.ni

Recepción: 06 Octubre 2020

Aprobación: 14 Diciembre 2020

URL: http://portal.amelica.org/ameli

jatsRepo/387/3871840009/index.html

DOI: https://doi.org/10.5377/torreon.v10i27.10842

El autor o los autores de los artículos, ensayos o investigaciones conceden a la Universidad Nacional Autónoma de Nicaragua, Managua (UNAN-Managua) los derechos de edición (copyright) del trabajo enviado, por consiguiente la Universidad cuenta con el derecho exclusivo para publicar el artículo durante el periodo completo de los derechos de autor.

\section{(i) $\ominus$}

Esta obra está bajo una Licencia Creative Commons AtribuciónNoComercial-SinDerivar 4.0 Internacional.
Resumen: La warfarina es un anticoagulante ampliamente usado a nivel mundial para la prevención y tratamiento de eventos tromboembólicos. Los polimorfismos en los genes CYP2C9 y VKORC1 -1639 se han asociado con la variabilidad de respuesta a la warfarina en diversas poblaciones. La identificación de la presencia de polimorfismos puede garantizar el uso más seguro y efectivo de warfarina al estimar la dosis adecuada para cada paciente. El objetivo de esta investigación es determinar la frecuencia de estos polimorfismos genéticos en la población latinoamericana. De los 402 artículos revisados, se incluyeron 11 estudios con datos de frecuencia de polimorfismos genéticos de 2,830 pacientes latinoamericanos. Las variantes alélicas CYP2C $9 * 1 / * 2$ y CYP2C $9 * 1 / * 3$ fueron más frecuentes en la población estudiada con un $13.15 \%$ y $6.93 \%$, respectivamente. La variante alélica ${ }^{*} 3 /{ }^{*} 3$ se presentó con una frecuencia de $0.17 \%$. En cuanto a los polimorfismos del gen VKORC1 - 1639 se reportaron frecuencias de $49.11 \%, 33$ $\%$ y $17 \%$ para las variantes GA, GG y AA, respectivamente. La frecuencia de polimorfismos en los genes CYP2C9 y VKORC1 -1639 en la población latinoamericana varía en dependencia del origen étnico de la población. En comparación con otras poblaciones se muestra un comportamiento similar al reportado en poblaciones de origen caucásico.

Palabras clave: warfarina, CYP2C9, VKORC1-1639, polimorfismos.

\begin{abstract}
Warfarin is the most common anticoagulant used worldwide for prevention and treatment of thromboembolic events. Polymorphisms in the CYP2C9 and VKORC1 -1639 genes have been associated with variability in the response to warfarin in several populations. The aim of this research is to determine the frequency of these polymorphisms in Latin American population. The identification of the presence of polymorphisms can guarantee the safest and most effective use of warfarin by predicting the appropriate dose for each patient. We included eleven studies with frequency data of genetic polymorphisms in 2,830 Latin American patients. The allelic variants CYP2C9 ${ }^{*} 1 /{ }^{*} 2$ and CYP2C9 ${ }^{*} 1 /{ }^{*} 3$ were more frequent in the study population, with $13.15 \%$ and $6.93 \%$
\end{abstract}




\begin{abstract}
respectively. The allelic variant $*^{*} 3 /{ }^{*} 3$ was present in $0.17 \%$. As for the polymorphisms of the VKORC1 -1639 gene frequencies of $49.11 \%, 33 \%$ and $17 \%$ were reported for the GA, GG and AA variants respectively. Frequency of the allelic variants in the genes CYPC9 and VKORC1, in the Latin American population, allows to establish starting points to suggest the genotypes that should be evaluated before the indication of the warfarin dose. Comparing the frequency of polymorphisms in the CYP2C9 and VKORC1 -1639 genes in the Latin American population with other populations, similarities are observed with the populations of origin.
\end{abstract}

Keywords: warfarin, CYP2C9, VKORC1-1639, polymorphism.

\section{INTRODUCCIÓN}

La variabilidad de respuesta a los medicamentos en individuos o poblaciones, desde el punto de vista farmacogenético, depende de las variaciones en la secuencia de ADN conocidas como polimorfismos (Arribas, 2010). Sabiendo el efecto de un determinado polimorfismo genético en la farmacocinética y farmacodinámica de un medicamento, es posible predecir la dosis adecuada, prevenir reacciones adversas y garantizar el uso más seguro y efectivo de este.

La mayoría de los estudios farmacogenéticos se han realizado en Europa, Norteamérica y Asia. Poco se sabe de marcadores farmacogenéticos en poblaciones latinoamericanas. Estas poblaciones tienden a presentar mezclas raciales muy variadas, de orígenes africanos, amerindios y europeos, por lo cual, la extrapolación de resultados farmacogenéticos de otras poblaciones con poblaciones latinoamericanas no resultaría correcta. Dicha realidad sugiere la necesidad de realizar estudios de caracterización farmacogenética en poblaciones de esta región (Céspedes, 2016).

La warfarina es un anticoagulante oral ampliamente usado para la prevención y tratamiento de eventos tromboembólicos (Gaikward , 2013; Kaye, 2017). El uso de warfarina reduce los casos de accidentes cerebrovasculares (ACV) en pacientes en un $60 \%$ aproximadamente (Li, 2015; Tsai, 2017; Miklosz, 2018). El manejo de la terapia anticoagulante con warfarina se vuelve complejo debido a la amplia variabilidad de respuesta inter e intra individual de pacientes (Parra, 2015; Al-Eitan, 2018). La dosificación inapropiada de warfarina incrementa significativamente el riesgo de tromboembolismo, sangrado, hospitalización y muerte en pacientes.

Los ajustes de dosis de warfarina son usualmente necesarios y se basan en la medición del tiempo de la protrombina (PT, Prothrombin Time) en sangre y el cálculo INR (International Normalized Ratio). Un valor alto de INR predispone a mayor riesgo de sangrado, mientras que un valor de INR por debajo del rango terapéutico, entre 2 y 3 , indica que la dosis de warfarina es insuficiente para proteger al paciente de eventos tromboembólicos (Kaye, 2017).

Muchos factores clínicos y ambientales como la edad, sexo, raza, índice de masa corporal, comorbilidades (principalmente enfermedades renales o hepáticas), polimedicación (Zhang,2016), consumo de tabaco, dieta, metabolismo rápido de vitamina $\mathrm{K}$, así como mutaciones genéticas afectan los requerimientos de dosis de warfarina (Bryk, 2018). Los polimorfismos genéticos en los genes de la subunidad 2C9 del complejo de citocromo P450 (CYP2C9) y la subunidad 1 del complejo de la vitamina K epóxido reductasa (VKORC1) se han asociado en un $40 \%$ a $60 \%$ con la variación en la respuesta interindividual a la warfarina (Flockhart, 2008; Dean, 2012; Tavares, 2018; Liu, 2017; Razavi, 2017; Wattanachai, 2017; Liu, 2017). 
La warfarina es una mezcla racémica de $S$-warfarina y $\mathrm{R}$-warfarina. La $\mathrm{S}$-warfarina es cinco veces más potente que la $\mathrm{R}$-warfarina y es la responsable del efecto anticoagulante en pacientes (Galvez, 2018). Dos variantes aminoacídicas, $\operatorname{Arg}_{144} \mathrm{Cys}$, que resultan de la sustitución de $\mathrm{C}_{430}$ por $\mathrm{T}$ en el exón 3 (CYP2C9*2), y $\mathrm{Ile}_{359} \mathrm{Leu}$, producido por la sustitución de $\mathrm{A}_{1075}$ por $\mathrm{C}$ en el exón 7 (CYP2C9*3) reducen la actividad catalítica de la enzima en comparación con la variante genética normal (gen nativo) CYP2C9*1. La actividad catalítica de la enzima resultante de la expresión del gen CYP2C9*3 es mucho menor que en los portadores de CYP2C9*2 y CYP2C9*1 (Dong, 2018). La eliminación de S-warfarina in vivo se reduce en un $66 \%$ y $90 \%$ en sujetos heterocigotos y homocigotos para el alelo CYP2C9*3, respectivamente, comparado con sujetos homocigotos CYP2C9*1 (Yoon, 2001). Se ha demostrado que los pacientes con las variantes alélicas CYP2C9*2 y CYP2C9*3 requieren dosis más bajas de warfarina (Dilge, 2016; Natarajan, 2013; Benavides, 2015).

La enzima vitamina $\mathrm{K}$ epóxido reductasa participa en la reducción de la Vitamina $\mathrm{K}$ (cofactor esencial para la activación de la $\gamma$-glutamil carboxilasa que cataliza la carboxilación de residuos de ácido glutámico en muchas proteínas involucradas en la coagulación sanguínea, factor II, VII, IX y X) (Moyer, 2009) activándola para su incorporación en la cascada de coagulación (ciclo de regeneración de vitamina $\mathrm{K}$, oxidación $\mathrm{y}$ reducción). El gen de la subunidad 1 del complejo de la vitamina $\mathrm{K}$ epóxido reductasa, VKORC1 es el responsable de la expresión de dicha enzima. La warfarina ejerce su efecto anticoagulante a través de la inhibición de los productos genéticos de VKORC1 (Cullell, 2018). Los portadores de VKORC1 -1639 GG requieren dosis más elevadas de warfarina en comparación con los portadores de las variantes GA y AA (Cavallari, 2011).

Pese a diversos estudios farmacogenéticos que explican la variabilidad de respuesta a la warfarina en distintas razas, las poblaciones afroamericanas y latinoamericanas no han sido significativamente representadas. Se ha demostrado que la variación de dosis de warfarina es mayor en poblaciones de descendencias mixtas, así, los latinos y los afroamericanos tienden a presentar mayor riesgo de respuesta inadecuada a la warfarina que podría resultar en casos de hemorragia intracraneal por un manejo subóptimo de este (Golwala,2016; Shen, 2007).

La caracterización de estas poblaciones en términos de biomarcadores de relevancia, ya identificados en estudios farmacogenéticos a nivel mundial, validará la utilidad de estas pruebas en el manejo clínico del paciente, promoviendo el uso más seguro y efectivo de este medicamento.

El objetivo de este estudio es identificar la frecuencia de polimorfismos genéticos CYP2C9 y VKORC1 -1639 en la población latinoamericana para sugerir el genotipo que debiera ser evaluado antes de la prescripción de warfarina.

\section{Desarrollo}

\section{Estrategia de búsqueda}

La búsqueda bibliográfica de artículos científicos se realizó en el período comprendido entre diciembre del 2017 a octubre del 2018. Las bases de datos consultadas fueron PubMed, HINARI y SciELO. La búsqueda se limitó a todos los estudios publicados en inglés y español, en el periodo de 2001 a 2018.

Las palabras claves utilizadas para la búsqueda fueron: warfarina, farmacogenética, polimorfismos genéticos, gen CYP2C9, gen VKORC1, Latinoamérica, reacciones adversas, hemorragia intracraneal y tromboembolismo. 


\section{Criterios de selección de estudios}

La selección de artículos científicos se realizó con base en los siguientes criterios de inclusión: pacientes que recibieron tratamiento con warfarina, pacientes latinoamericanos, pacientes con polimorfismos genéticos CYP2C9 y VKORC1; y reporte de frecuencias de polimorfismos en los genes CYP2C9 y VKORC1.

\section{Análisis estadístico}

El análisis estadístico de los datos se realizó con el programa Minitab 17. Para el análisis de datos de los polimorfismos del gen CYP2C9 se aplicó el contraste de Grubbs para identificar datos anómalos y la prueba de normalidad de Anderson Darling para determinar si los datos seguían una distribución normal con un nivel de confianza del $95 \%$.

En cuanto a los datos de polimorfismos genéticos del gen VKORC1 -1639 se aplicó únicamente el test de Grubbs. Debido al tamaño de la muestra (siete artículos) no es posible la aplicación concluyente de la prueba de normalidad.

La desviación del equilibrio de Hardy-Weinberg se evaluó por separado para cada polimorfismo dentro de cada grupo de estudio haciendo uso de la prueba de $\mathrm{X}^{2}$ con un grado de libertad y un nivel de significancia de 0.050 (Limdi, 2010; Cabrero).

\section{Selección de los estudios}

Se encontraron 402 artículos científicos referidos a la farmacogenética de la warfarina, de estos 382 fueron excluidos por no incluir población latinoamericana. Se identificaron 20 artículos realizados en población latinoamericana, de estos, sólo once cumplieron con los criterios de inclusión, los restantes nueve artículos (Tavares, 2018; Liu, 2017; Valentín, 2014; Guerrero, 2009; Isaza, 2010; Raggio, 2005; Claudio-Campos, 2015; Parra, 2015; Villagra, 2010) fueron excluidos (Fig. 1). Los países latinoamericanos con mayor número de publicaciones son Puerto Rico (seis artículos; dos incluidos) y Brasil (cinco artículos; tres incluidos), seguidos de México (dos artículos; ambos incluidos), Chile (dos artículos; ambos incluidos), Colombia y Argentina (un artículo por país, ambos incluidos). De los artículos seleccionados, nueve fueron publicados en inglés y dos en español. 


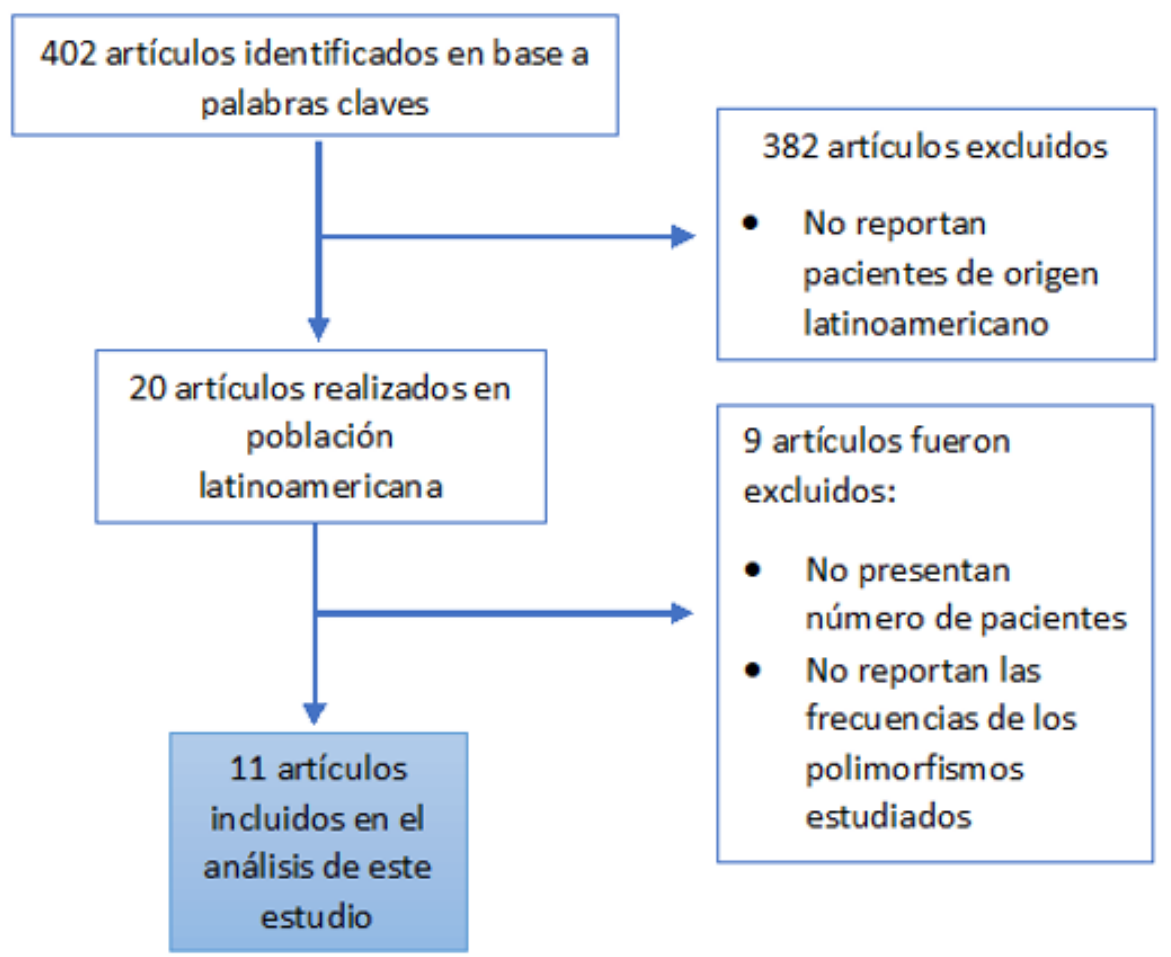

FIGURA 1.

Diagrama de selección de estudios.

\section{Características del estudio}

Los 2,830 pacientes incluidos eran de origen latinoamericano. Las indicaciones de warfarina fueron reportadas sólo en cinco estudios, siendo las más frecuentes la fibrilación auricular (FA), las prótesis valvulares (PV), tromboembolismo (TE), trombosis venosa profunda (TVP) y accidente cerebrovascular (ACV).

De los once artículos, todos estudiaron los polimorfismos genéticos de CYP2C9 (2,830 pacientes), siete (1,236 pacientes) presentaron los polimorfismos del gen VKORC1 -1639 y siete (1,219 pacientes) analizaron los dos genotipos CYP2C9 y VKORC1 - 1639.

La Tabla 1 resume las características de los estudios. 
TABLA 1.

Datos de los estudios analizados

\begin{tabular}{|c|c|c|c|c|c|c|c|c|c|c|c|c|c|c|}
\hline \multirow{3}{*}{ No } & \multirow{3}{*}{ Estudio } & \multirow{3}{*}{ Ubicación } & \multirow{3}{*}{$\begin{array}{l}\text { Indicación de } \\
\text { warfarina }\end{array}$} & \multirow{3}{*}{$\begin{array}{l}\text { Número } \\
\text { de } \\
\text { pacientes }\end{array}$} & \multirow{3}{*}{ Edad } & \multicolumn{9}{|c|}{ Frecuencia Genotípica } \\
\hline & & & & & & \multicolumn{6}{|c|}{ CYP2C9\% (n) } & \multicolumn{3}{|c|}{$\begin{array}{c}\text { VKORC1 -1639\% } \\
\text { (n) }\end{array}$} \\
\hline & & & & & & ${ }^{*} 1 /{ }^{*} 1$ & ${ }^{*} 1 / /^{*} 2$ & ${ }^{*} 1 /{ }^{*} 3$ & ${ }^{*} 2 /{ }^{*} 2$ & $* 2 /{ }^{*} 3$ & $* 3 / * 3$ & \begin{tabular}{|l|}
$\mathrm{AA}$ \\
\end{tabular} & \begin{tabular}{|l|l}
$\mathrm{GA}$ \\
\end{tabular} & GG \\
\hline 1 & $\begin{array}{l}\text { Perini } \\
\text { et.al. } \\
\text { (2009) }\end{array}$ & $\begin{array}{l}\text { Brasil, } \\
\text { descendencia } \\
\text { mixta } \\
\end{array}$ & - & 331 & - & \begin{tabular}{|l|}
72.2 \\
$\%$ \\
$(239)$ \\
\end{tabular} & \begin{tabular}{|l|}
14.5 \\
$\%$ \\
$(48)$
\end{tabular} & \begin{tabular}{|l|}
10.9 \\
$\%$ \\
$(36)$ \\
\end{tabular} & $\begin{array}{l}0.9 \% \\
(3)\end{array}$ & $\begin{array}{l}0.9 \% \\
(3)\end{array}$ & $\begin{array}{l}0.6 \% \\
(2)\end{array}$ & - & - & - \\
\hline 2 & $\begin{array}{l}\text { Botton, } \\
\text { et.al } \\
\text { (2011) }\end{array}$ & $\begin{array}{l}\text { Brasil, } \\
\text { descendencia } \\
\text { española }\end{array}$ & FA PV TE ACV TF & 279 & $\begin{array}{l}62.6 \\
(18-88)\end{array}$ & \begin{tabular}{|l|}
65.2 \\
$\%$ \\
$(182)$
\end{tabular} & \begin{tabular}{|l|}
22.9 \\
$\%$ \\
$(64)$
\end{tabular} & $\begin{array}{l}9.0 \% \\
(25)\end{array}$ & $\begin{array}{l}1.1 \% \\
(3)\end{array}$ & $\begin{array}{l}1.8 \% \\
(5)\end{array}$ & $0(0)$ & $\begin{array}{l}13.6 \\
\% \\
(38)\end{array}$ & \begin{tabular}{|l|}
$46.2 \%$ \\
$(129)$
\end{tabular} & $\begin{array}{l}40.2 \% \\
(112)\end{array}$ \\
\hline 2 & $\begin{array}{l}\text { Miranda } \\
\text { et.al } \\
\text { (2011) }\end{array}$ & Chile & - & 24 & $\begin{array}{l}25 \\
(18-55)\end{array}$ & $\begin{array}{l}79.2 \\
\%(19)\end{array}$ & $\begin{array}{l}16.7 \\
\%(4)\end{array}$ & $(0)$ & $\begin{array}{l}4.2 \% \\
(1)\end{array}$ & (0) & $(0)$ & - & - & - \\
\hline 4 & \begin{tabular}{|l|} 
Valentina \\
et.al \\
$(2012)$ \\
\end{tabular} & $\begin{array}{l}\text { Puerto Rico, } \\
\text { descendencia } \\
\text { mixta } \\
\end{array}$ & \begin{tabular}{|l|} 
FA TVPEP \\
ACVRVAAITFCCRVMB \\
BABF IM, EVA EACI \\
\end{tabular} & $103(101)$ & 67.2 & $\begin{array}{l}59 \% \\
(61)\end{array}$ & $\begin{array}{l}25 \% \\
(26)\end{array}$ & $\begin{array}{l}5 \% \\
(5)\end{array}$ & $\begin{array}{l}3 \% \\
(3)\end{array}$ & $\begin{array}{l}6 \% \\
(6)\end{array}$ & $0(0)$ & \begin{tabular}{|l|}
14.7 \\
$\%$ \\
$(15)$ \\
\end{tabular} & $\begin{array}{l}52 \% \\
(54)\end{array}$ & $\begin{array}{l}33 \% \\
(34)\end{array}$ \\
\hline 5 & \begin{tabular}{|l|} 
Scibona \\
et.al \\
$(2012)$ \\
\end{tabular} & Argentina & - & 101 & \begin{tabular}{|l|}
35 \\
$(21-67)$
\end{tabular} & $\begin{array}{l}56 \% \\
(57)\end{array}$ & $\begin{array}{l}23 \% \\
(24)\end{array}$ & $\begin{array}{l}4 \% \\
(5)\end{array}$ & $\begin{array}{l}13 \% \\
(14)\end{array}$ & $\begin{array}{l}1 \% \\
(1)\end{array}$ & $0(0)$ & \begin{tabular}{|l|}
20 \\
$\%$ \\
$(21)$
\end{tabular} & $\begin{array}{l}60 \% \\
(60)\end{array}$ & $\begin{array}{l}19 \% \\
(20)\end{array}$ \\
\hline 6 & \begin{tabular}{|l|} 
Castelan \\
et.al \\
$(2013)$ \\
\end{tabular} & $\begin{array}{l}\text { México, } \\
\text { mestizos }\end{array}$ & - & 947 & 58 & $\begin{array}{l}83 \% \\
(788)\end{array}$ & $\begin{array}{l}8.7 \% \\
(82)\end{array}$ & $\begin{array}{l}6.8 \% \\
(64)\end{array}$ & $\begin{array}{l}0.4 \% \\
(4)\end{array}$ & $\begin{array}{l}0.7 \% \\
(7)\end{array}$ & $\begin{array}{l}0.2 \% \\
(2)\end{array}$ & - & - & - \\
\hline 7 & \begin{tabular}{|l|} 
Botton \\
et.al \\
$(2014)$ \\
\end{tabular} & \begin{tabular}{|l|} 
Brasil, \\
descendencia \\
española \\
\end{tabular} & FA. PV, TE, ACV, TF & 198 & \begin{tabular}{|l|}
60.5 \\
$(28-97)$
\end{tabular} & \begin{tabular}{|l|}
66.7 \\
$\%$ \\
$(132)$ \\
\end{tabular} & \multicolumn{4}{|c|}{$33.3 \%(66)$} & $0(0)$ & \begin{tabular}{|l|}
12.6 \\
$\%$ \\
$(25)$ \\
\end{tabular} & \begin{tabular}{|l|}
50.5 \\
$\%$ \\
$(100)$ \\
\end{tabular} & $\begin{array}{l}36.9 \\
\% \\
(73)\end{array}$ \\
\hline 8 & \begin{tabular}{|l|} 
Villegas \\
et.al \\
$(2015)$ \\
\end{tabular} & \begin{tabular}{|l} 
México, \\
mestizos
\end{tabular} & - & 292 & - & $\begin{array}{l}79 \% \\
(233)\end{array}$ & \begin{tabular}{|l|}
12.9 \\
$\%$ \\
$(38)$ \\
\end{tabular} & $\begin{array}{l}6.8 \% \\
(20)\end{array}$ & $\begin{array}{l}0.3 \% \\
(1)\end{array}$ & 0 & 0 & - & - & - \\
\hline 9 & $\begin{array}{l}\text { Benavides } \\
\text { et.al } \\
\text { (2015) } \\
\end{array}$ & Chile & - & 170 & - & \begin{tabular}{|l|}
70.6 \\
$\%$ \\
$(120)$ \\
\end{tabular} & \begin{tabular}{|l|}
17.1 \\
$\%$ \\
$(29)$
\end{tabular} & \begin{tabular}{|l|}
7.65 \\
$\%$ \\
$(13)$ \\
\end{tabular} & $\begin{array}{l}1.17 \\
\%(2)\end{array}$ & $\begin{array}{l}2.94 \\
\%(5)\end{array}$ & $\begin{array}{l}0.58 \\
\%(1)\end{array}$ & \begin{tabular}{|l|}
25.3 \\
$\%$ \\
$(43)$ \\
\end{tabular} & \begin{tabular}{|l|}
49.4 \\
$\%$ \\
$(84)$ \\
\end{tabular} & $\begin{array}{l}25.3 \\
\% \\
(43)\end{array}$ \\
\hline 10 & $\begin{array}{l}\text { Cifuentes } \\
\text { et.al } \\
\text { (2016) }\end{array}$ & $\begin{array}{l}\text { Colombia, } \\
\text { descendencia } \\
\text { mixta }\end{array}$ & $\begin{array}{l}\text { PV, TVP, FA, EP, ACV, } \\
\text { EC, SAFL, DV }\end{array}$ & 130 & \begin{tabular}{|l|}
66.2 \\
$(28-88)$
\end{tabular} & $\begin{array}{l}77 \% \\
(100)\end{array}$ & $\begin{array}{l}14.7 \\
\% \\
(19)\end{array}$ & $\begin{array}{l}7.7 \% \\
(10)\end{array}$ & $\begin{array}{l}0.8 \% \\
(1)\end{array}$ & $0(0)$ & $0(0)$ & $\begin{array}{l}35.4 \\
\% \\
(46)\end{array}$ & $\begin{array}{l}43.1 \\
\% \\
(56) \\
\end{array}$ & $\begin{array}{l}21.5 \\
\% \\
(28)\end{array}$ \\
\hline 11 & $\begin{array}{l}\text { Ducongec } \\
\text { et.al } \\
(2016) \\
\end{array}$ & $\begin{array}{l}\text { Puerto Rico, } \\
\text { hispano } \\
\text { caribeños }\end{array}$ & FA, TVP, EP & $255(240)$ & $\begin{array}{l}68.1 \\
(31-94)\end{array}$ & $\begin{array}{l}70 \% \\
(179)\end{array}$ & \begin{tabular}{|l|}
14.1 \\
$\%$ \\
$(36)$ \\
\end{tabular} & $\begin{array}{l}6.7 \% \\
(17)\end{array}$ & $\begin{array}{l}0.8 \\
(2)\end{array}$ & $\begin{array}{l}2.4 \% \\
(6)\end{array}$ & $0(0)$ & \begin{tabular}{l|}
13 \\
$\%$ \\
$(33)$ \\
\end{tabular} & \begin{tabular}{|l|}
48.6 \\
$\%$ \\
$(124)$ \\
\end{tabular} & $\begin{array}{l}38.4 \\
\% \\
(98) \\
\end{array}$ \\
\hline & \multicolumn{3}{|c|}{ Total de pacientes } & 2,830 & - & 1,978 & 370 & 195 & 34 & 33 & 5 & 221 & 607 & 408 \\
\hline
\end{tabular}

FA-Fibrilación auricular; PV-Prótesis valvulares; TE-Tromboembolismo; TF-trombofilia; EP-Embolia Pulmonar;EC-Enfermedad Coronaria; SAFL-Síndrome Antifosfolipídico; DV-Dilatación Ventricular; TVP-trombosis venosa profunda; EP-Embolia Pulmonar; RVA-remplazo de válvula auricular; AIT-Ataque isquémico transitorio; FCC-fallo cardíaco congestivo; RVMB-reemplazo de válvula mitral bioprostético; IM-infarto del miocardio; EVA-enfermedad válvulas aórtica; EACI-estenosis arterial carótida interna.

Valentin ${ }^{\mathrm{a}}$ - Dos pacientes de este estudio dieron positivo a los polimorfismos CYP2C9 ${ }^{*} 1 /{ }^{*} 5 \mathrm{y} * 2 /{ }^{*} 5$ no tomados en cuenta en este estudio, por tanto, la población total para este polimorfismo fue de 101 pacientes, señalado entre paréntesis () en la tabla.

Botton $^{\mathrm{b}}$ - Los datos de los polimorfismos del gen CYP2C, reportados en este estudio no se tomaron en cuenta en el análisis debido a que no presentan específicamente los alelos encontrados.

Duconge ${ }^{c}$ - Quince pacientes de este estudio presentaron otros polimorfismos en el gen

CYP2C9 que no fueron tomados en cuenta en este estudio, por tanto, la población total para este polimorfismo fue de 240 pacientes, señalado entre paréntesis () en la tabla.

\section{Polimorfismos en el gen CYP2C9}

La frecuencia alélica de CYP2C9 en las poblaciones latinoamericanas estudiadas se muestra en la Tabla 1. El alelo nativo CYP2C9*1/*1 homocigoto presenta una frecuencia entre 56-83\%, siendo la población mexicana mestiza la que presentó la frecuencia más alta $(83 \%)$ y la población argentina la más baja (56\%).

Las poblaciones de origen mixto presentan frecuencias distintas en relación a las poblaciones de origen español. Si se compara la población de Brasil de descendencia mixta con la población de descendencia española se puede observar diferencias entre los valores de frecuencia genótipica CYP2C9 hasta dos veces el valor, como ocurre con el alelo ${ }^{*} 2 /{ }^{*} 3$ que se presenta en una frecuencia de $0.9 \%$ y $1.8 \%$ para cada población (Tabla 1). 
Los alelos CYP2C9*1/*2 y CYP2C9*1/*3 presentaron frecuencias entre $12.9 \%-25 \%$ y 4 \%-10.9 \% respectivamente. Junto con el alelo nativo (CYP2C $\left.9 * 1 /{ }^{*} 1\right)$ estos valores de frecuencia son los más altos en comparación con el resto de alelos estudiados.

Los valores de frecuencia encontrados en este estudio para los alelos CYP2C9*2/*2 y CYP2C9*2/ *3 oscilan entre $0.3 \%$ a $13 \%$ y $0.7 \%-6.0 \%$, respectivamente. El alelo homocigoto CYP2C9*2/*2 tuvo representatividad en todos los estudios analizados (34 pacientes). En cuanto al alelo heterocigoto CYP2C9*2/*3 se reportó en nueve estudios con un total de 33 pacientes.

Los polimorfismos ${ }^{*} 2 /{ }^{*} 2$ y ${ }^{*} 2 /{ }^{*} 3$ de los pacientes de Argentina y Puerto Rico con descendencia mixta se presentaron con una frecuencia atípica con respecto al resto de la población estudiada, de $13 \%$ y $6 \%$ respectivamente. Esto hace que la distribución de los datos para estos polimorfismos no sea normal aplicando la prueba de Anderson Darling (Anexo 1).

En cuanto al polimorfismo ${ }^{*} 3 /{ }^{*} 3$ se encontró una frecuencia muy baja en la población, cinco pacientes de un total de 2, 813. Los datos para este polimorfismo se distribuyen normalmente. La frecuencia de distribución de alelos polimórficos del gen CYP2C9 se muestra en la gráfica 1.

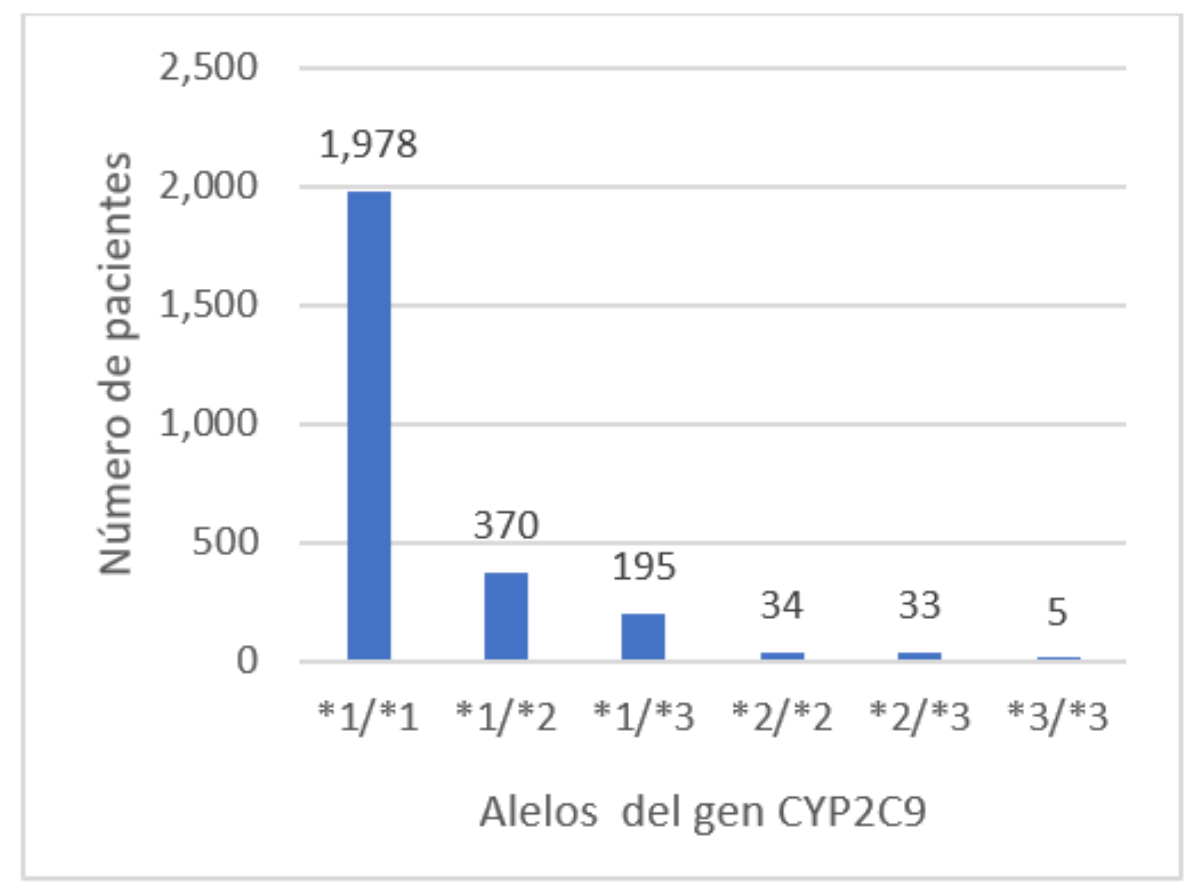

GRÁFICA 1.

Frecuencia de polimorfismos del gen CYP2C9 en la población estudiada.

El análisis estadístico de la frecuencia de polimorfismos en las poblaciones estudiadas, aplicando el contraste de Grubbs para identificar datos atípicos y el estadístico de Anderson Darling para la prueba de normalidad determinó que para $\operatorname{los}$ alelos ${ }^{*} 1 /{ }^{*} 1,{ }^{*} 1 /{ }^{*} 2 \mathrm{y} * 1 /{ }^{*} 3$ no hay datos anómalos y los datos siguen una distribución normal (Anexo 1).

La comparación de la frecuencia de polimorfismos en los genes CYP2C9 en población latinoamericana con respecto a otras poblaciones del mundo se muestran en la gráfica 2. La frecuencia de los alelos CYP2C9 ${ }^{*} 1 /{ }^{*} 2$ y CYP2C ${ }^{*} 1 /{ }^{*} 3(17 \%$ y $7.17 \%)$ en la población estudiada se asemeja a los resultados obtenidos en poblaciones de origen caucásicos con frecuencia de $19 \%$ y $12 \%$ respectivamente (Kliegman; Zhang, 2016).

Las variantes ${ }^{*} 2 /{ }^{*} 2$ y ${ }^{*} 2 /{ }^{*} 3$ en la población estudiada presentan una frecuencia de $2.5 \%$ y $2.25 \%$, valores que difieren de las poblaciones asiáticas, africanas, caucásicas e indias, cuyas frecuencias se encuentran en un rango de $0 \%$ a $1.4 \%$. La variante $* 3 /{ }^{*} 3$ se presenta en una frecuencia similar a la observada en la población caucásica, $0.46 \%$ y $0.5 \%$ respectivamente. 


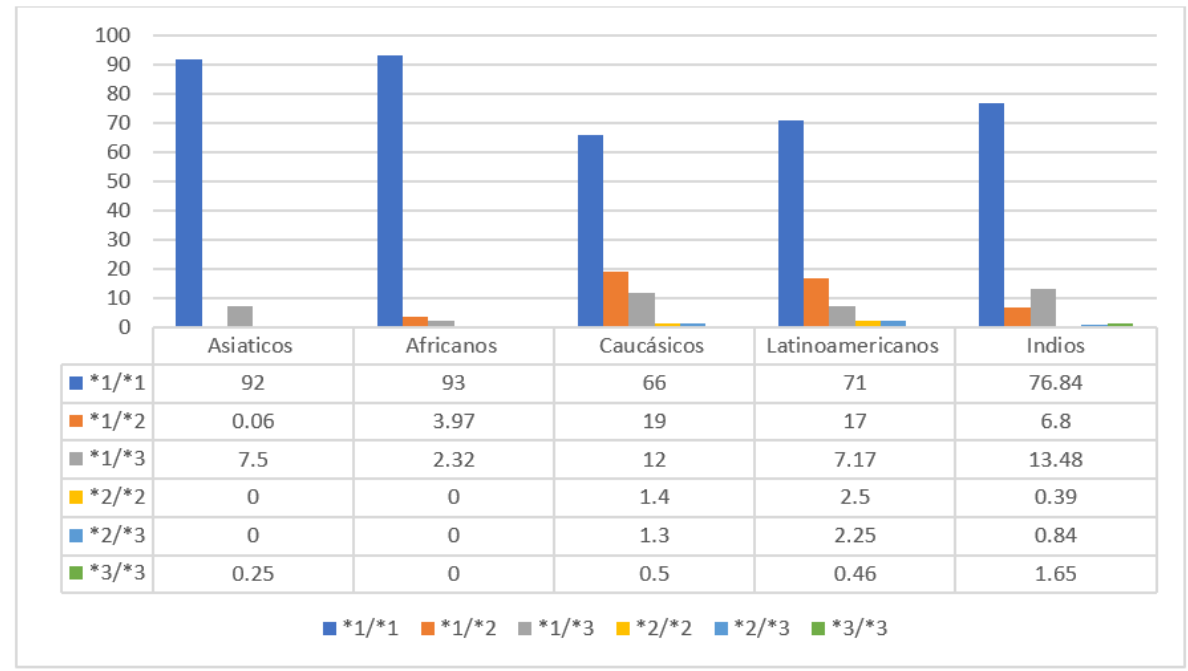

GRÁFICA 2.

Comparación de frecuencia de genotipos CYP2C9 en diversas poblaciones.

Los valores de frecuencia de las poblaciones asiáticas, africanas, caucásicas e indias fueron obtenidos del estudio de Zhang, 2016; en el caso de la población asiática se calculó el valor medio de las poblaciones de chinos-han, japoneses y coreanos. Los datos de la población latinoamericana son los valores medios de los datos reportados en los 11 artículos en estudio.

\section{Polimorfismos genéticos en el gen VKORC1 -1639}

En la gráfica 3, se observan las frecuencias de polimorfismos del gen VKORC1 -1639 encontrados en la población latinoamericana.

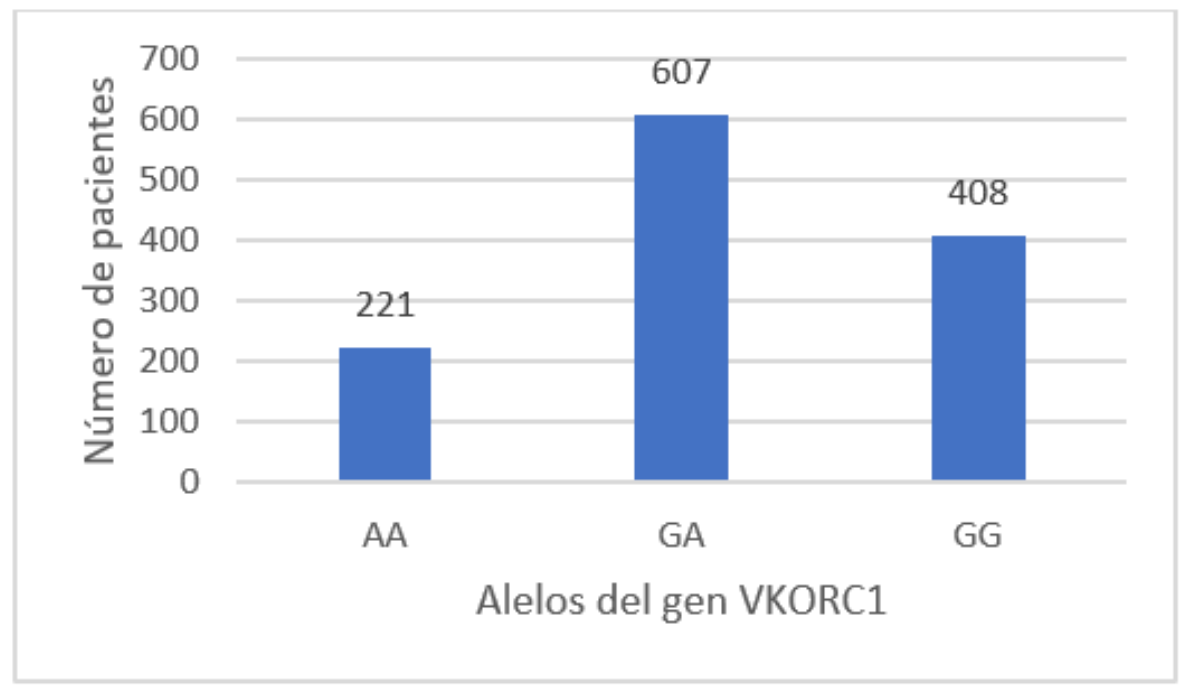

GRÁFICA 3.

Frecuencia de polimorfismos del gen VKORC -1639

El polimorfismo más frecuente del gen VKORC1 -1639 fue el alelo heterocigoto GA con 49.11 \% (607 pacientes), seguido del alelo GG con $33 \%$ (408 pacientes) y del alelo AA $17.88 \%$ (221 pacientes). No se identificaron datos anómalos en la población estudiada al aplicar el estadístico de Grubbs (Anexo 1). 
En la Gráfica 4 se observa la comparación de la frecuencia de la variante GA del gen VKORC1 -1639 en la población estudiada con la frecuencia observada en la población de origen caucásico, las cuales presentan valores muy cercanos de $49.97 \%$ y $49 \%$ respectivamente. En relación a las frecuencias del gen nativo GG y la variante AA los valores de ambas poblaciones se distribuyen en rangos cercanos de $30 \%$ a $36 \%$ y $15 \%$ a $19 \%$ para cada uno. Las frecuencias de estas variantes en las poblaciones asiáticas, africanas e indias no presentan similitudes con la población estudiada.

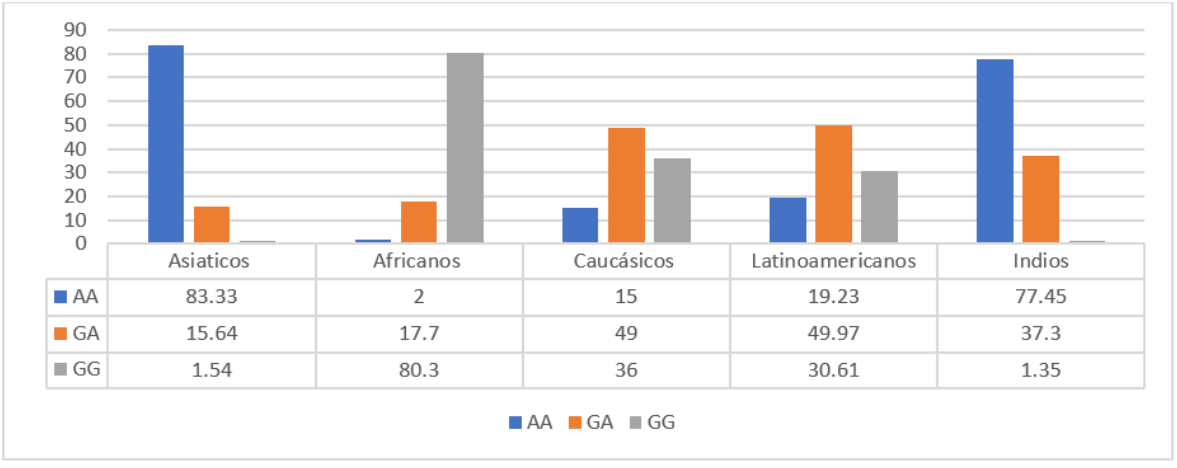

GRÁFICA 4.

Comparación de frecuencia de genotipos VKORC1-1639 en diversas poblaciones.

Una de las limitantes al estudiar los polimorfismos genéticos CYP2C9 y VKORC1 -1639 en población latinoamericana, en la diversidad étnica de esta región. Las frecuencias genotípicas de CYP2C9 y VKORC1 -1639 varían en dependencia del origen étnico. Al ser la población latinoamericana una población mixta que ha experimentado diversos procesos migratorios a través de su historia, se espera un incremento del carácter heterocigótico dentro de dichas poblaciones. Las características migratorias propias de cada país han influido en la diversidad de mezclas raciales a lo largo de la región.

A pesar de que se han publicado artículos sobre la frecuencia de polimorfismos CYP2C9 y VKORC1 -1639 en Latinoamérica, no se han realizado análisis comparativos de estas poblaciones con otros grupos poblacionales. En ese sentido, este estudio representa el primer esfuerzo en compilar la información existente permitiendo determinar el estado actual e identificar los vacíos de conocimiento como la información inexistente sobre la frecuencia de estos polimorfismos en la región centroamericana.

En este estudio se encontró que la frecuencia de los alelos CYP2C9 ${ }^{*} 1 /{ }^{*} 2$ y CYP $2 \mathrm{C} 9 * 1 / * 3$ en la población latinoamericana se asemeja a los resultados obtenidos en poblaciones de origen caucásicos (Kliegman; Zhang, 2016). Limdi et al (2008) reportan una frecuencia de $19 \%$ y $12 \%$ en la población caucásica. En la población latinoamericana estas dos variantes se presentan en mayor frecuencia con respecto a las variantes ${ }^{*} 2 /{ }^{*} 2,{ }^{*} 2 /$ ${ }^{*} 3 y^{*} 3 /{ }^{*} 3$, por lo que deben de tomarse en cuenta en los análisis farmacogenéticos para el ajuste de dosis de warfarina.

La frecuencia de las variantes $* 2 /{ }^{*} 2$ y ${ }^{2} /{ }^{*} 3$ en la población latinoamericana difieren de las poblaciones asiáticas, africanas, caucásicas e indias. Según, Seng et al. (2003), Daneshjou (2013) y Gaikward et al. (2013) tanto la población asiática como africana presentan frecuencias nulas para el alelo ${ }^{*} 2 /{ }^{*} 2$. Ocurre un fenómeno parecido en la población de origen indio reportándose frecuencias de $0.39 \%$. Los valores altos de estas variantes reportadas en la población latinoamericana se deben a frecuencias de $13 \%$ para el alelo ${ }^{*} 2 /{ }^{*} 2$ identificadas en la población argentina, $6.0 \%$ y $2.94 \%$ para el alelo ${ }^{*} 2 /{ }^{*} 3$ reportadas en la población puertorriqueña (descendencia mixta) y chilena respectivamente.

Puesto que estas tres poblaciones presentan valores particularmente diferentes en comparación con otros grupos étnicos, las variantes ${ }^{*} 2 /{ }^{*} 2 \mathrm{y}^{*} 2 /{ }^{*} 3$ deben de evaluarse en estudios farmacogenéticos de la región ya que pueden representar una característica étnica específica de la población latinoamericana. 
La variante homocigótica $* 3 / * 3$ presenta una frecuencia media similar a la frecuencia reportada en la población caucásica. Según Zhang J., et al. (2016), los pacientes que presentan esta variante alélica rara requieren dosis de warfarina mucho más bajas en relación a los portadores de la variante alélica nativa ${ }^{*} 1 /{ }^{*} 1$; si recibieran la misma dosis tendrían mayor riesgo de sufrir hemorragias en comparación con los portadores del alelo nativo.

En cuanto al gen VKORC1 -1639, las frecuencias de las variantes GA, AA y GG presentadas en la población coinciden con la población caucásica, sin embargo, al comparar con los resultados obtenidos en poblaciones asiáticas, africanas e indias se observan diferencias importantes. Las poblaciones asiáticas e indias presentan las frecuencias más altas de AA y las más bajas de GG ubicándose en los extremos, en tanto la población africana es la única en presentar la frecuencia más alta del GG, 2.6 veces más que la población latinoamericana.

Este análisis permite establecer un criterio de predicción de dosis con base en la descendencia cercana de los pacientes valorados durante la consulta. Según Flockhart D. et al (2008) los pacientes que presenten rasgos fenotípicos de descendencia africana o asiática pueden clasificarse en individuos con baja sensibilidad (frecuencia alta de GG) y alta sensibilidad (frecuencia alta de AA) a la warfarina, esto indica un incremento de dosis de $35 \%$ para el primer caso y una disminución de dosis de $32 \%$ para los portadores de AA. Esto coincide con lo que afirma Hosseinkhani Z., et al (2018), que los individuos que presentan mutaciones (AA o $\mathrm{AG}$ ) requieren menores dosis de warfarina en comparación con aquellos que no presentan mutaciones (GG).

En nueve de los diez estudios analizados las distribuciones genotípicas para CYP2C9 y VKORC1 - 1639 estuvieron en equilibrio de Hardy-Weinberg dentro de cada grupo, detectándose una desviación significativa en la población argentina, la cual presenta un valor atípico que se debe posiblemente al tamaño reducido de la muestra (Anexo 2).

Las implicaciones de este estudio se centran en poner en perspectiva los estudios farmacogenéticos realizados en la región y sus aportes en disminuir los vacíos de conocimiento en cuanto a variantes genéticas para ayudar a direccionar la traslación de conocimientos farmacogenéticos a la población latinoamericana que ha sido subestimadas en estudios farmacogenéticos mundiales.

\section{Conclusiones}

La frecuencia de variantes alélicas en los genes CYPC9 y VKORC1 en la población latinoamericana, permite establecer un punto de partida para indicar los genotipos que deben ser evaluados previo a la prescripción de warfarina. Así, las variantes ${ }^{*} 1 /{ }^{*} 1,{ }^{*} 1 /{ }^{*} 2,{ }^{*} 1 /{ }^{*} 3$ del gen CYP2C9 y GA, GG y AA del gen VKORC1 -1639 deben de evaluarse en la población latinoamericana al presentarse en altas frecuencias. En cuanto a similitudes encontradas con otras poblaciones, la frecuencia de polimorfismos en los genes CYP2C9 y VKORC1 - 1639 en la población latinoamericana muestra un comportamiento similar al reportado en poblaciones de origen caucásico.

Se identificó una característica particular en la población latinoamericana en relación a la frecuencia de los alelos ${ }^{*} 2 /{ }^{*} 2 y^{*} 2 /{ }^{*} 3$. Estos se presentan con frecuencias distantes en comparación con otros grupos étnicos pudiendo ser una característica específica de esta población que debe ser estudiada a mayor profundidad en investigaciones futuras.

\section{Referencias Bibliográficas}

Al-Eitan, L. N., Almasri, A. Y., \& Khasawneh, R. H. (2018). Impact of CYP2C9 and VKORC1 Polymorphisms on Warfarin Sensitivity and Responsiveness in Jordanian Cardiovascular Patients during the Initiation Therapy. Genes, 9(12), 578. https://doi.org/10.3390/genes9120578 
Arribas IA. (2010). Farmacogenética y variabilidad interindividual en la respuesta a los medicamentos. Academia de Farmacia "Reino de Aragón. http://www.academiadefarmaciadearagon.es/docs/documentos/documento21.pdf

Benavides, F., Grossman, N., Poggi, H., Nieto, E., Bertrán, A., Araos, D., Vásquez, M., Ibarra, I., Cáceres, F., Espinoza, K., Lagos, M., \& Repetto M, G. (2015). Efecto de las variantes de VKORC1 y CYP2C9 sobre la dosis de anticoagulantes orales en individuos chilenos Revista medica de Chile, 143(11), 1369-1376.

Botton, M. R., Bandinelli, E., Rohde, L. E., Amon, L. C., \& Hutz, M. H. (2011). Influence of genetic, biological and pharmacological factors on warfarin dose in a Southern Brazilian population of European ancestry. British journal of clinical pharmacology, 72(3), 442-450. https://doi.org/10.1111/j.1365-2125.2011.03942.x

Bryk, A. H., Wypasek, E., Plens, K., Awsiuk, M., \& Undas, A. (2018). Bleeding predictors in patients following venous thromboembolism treated with vitamin $\mathrm{K}$ antagonists: Association with increased number of single nucleotide polymorphisms. Vascular pharmacology, 106, 22-27. https://doi.org/10.1016/j.vph.2018.02.002

Castelán-Martínez, O. D., Hoyo-Vadillo, C., Sandoval-García, E., Sandoval-Ramírez, L., González-Ibarra, M., SolanoSolano, G., Gómez-Díaz, R. A., Parra, E. J., Cruz, M., \& Valladares-Salgado, A. (2013). Allele frequency distribution of CYP2C9 2 and CYP2C9 3 polymorphisms in six Mexican populations. Gene, 523(2), 167-172. https://doi.org/10.1016/j.gene.2013.03.128

Cavallari, L. H., Shin, J., \& Perera, M. A. (2011). Role of pharmacogenomics in the management of traditional and novel oral anticoagulants. Pharmacotherapy, 31(12), 1192-1207. https://doi.org/10.1592/phco.31.12.1192

Céspedes-Garro, C., Naranjo, M. G., Rodrigues-Soares, F., LLerena, A., Duconge, J., Montané-Jaime, L. K., Roblejo, H., Fariñas, H., Campos, M. L., Ramírez, R., Serrano, V., Villagrán, C. I., \& Peñas-LLedó, E. M. (2016). Pharmacogenetic research activity in Central America and the Caribbean: a systematic review. Pharmacogenomics, 17(15), 1707-1724. https://doi.org/10.2217/pgs-2016-0053

Cifuentes, R., Murillo, J. y Avella, E. (2016). Predicción a la sensibilidad a la warfarina con base en polimorfismos de los genes VKORC1 y CYP2C9 en pacientes colombianos. Biomédica, 36, 91-100.

Claudio-Campos, K., Orengo-Mercado, C., Renta, J. Y., Peguero, M., García, R., Hernández, G., Corey, S., Cadilla, C. L., \& Duconge, J. (2015). Pharmacogenetics of healthy volunteers in Puerto Rico. Drug metabolism and personalized therapy, 30(4), 239-249. https://doi.org/10.1515/dmpt-2015-0021

Cullell, N., Carrera, C., Muiño, E., Torres, N., Krupinski, J., \& Fernandez-Cadenas, I. (2018). Pharmacogenetic studies with oral anticoagulants. Genome-wide association studies in vitamin $\mathrm{K}$ antagonist and direct oral anticoagulants. Oncotarget, 9(49), 29238-29258. https://doi.org/10.18632/oncotarget.25579

Daneshjou, R., Tatonetti, N. P., Karczewski, K. J., Sagreiya, H., Bourgeois, S., Drozda, K., Burmester, J. K., Tsunoda, T., Nakamura, Y., Kubo, M., Tector, M., Limdi, N. A., Cavallari, L. H., Perera, M., Johnson, J. A., Klein, T. E., \& Altman, R. B. (2013). Pathway analysis of genome-wide data improves warfarin dose prediction. BMC genomics, 14 Suppl 3(Suppl 3), S11.

Dean, L. (2012). Warfarin Therapy and VKORC1 and CYP Genotype. In V. M. Pratt (Eds.) et. al., Medical Genetics Summaries. National Center for Biotechnology Information (US).

Dilge Taşkın, B., Kula, S., Ergün, M. A., Altun, D., Olguntürk, R., Tunaoğlu, F. S., Oğuz, A. D., \& Gürsel, T. (2016). The effect of CYP2C9 and VKORC1 genetic polymorphisms on warfarin dose requirements in a pediatric population. Anatolian journal of cardiology, 16(10), 791-796. https://doi.org/10.14744/ AnatolJCardiol.2015.6150

Dong, A. N., Tan, B. H., Pan, Y., \& Ong, C. E. (2018). Cytochrome P450 genotype-guided drug therapies: An update on current states. Clinical and experimental pharmacology \& physiology, 45(10), 991-1001. https:// doi.org/10.1111/1440-1681.12978

Duconge, J., Cadilla, C. L., Windemuth, A., Kocherla, M., Gorowski, K., Seip, R. L., Bogaard, K., Renta, J. Y., Piovanetti, P., D'Agostino, D., Santiago-Borrero, P. J., \& Ruaño, G. (2009). Prevalence of combinatorial CYP2C9 and VKORC1 genotypes in Puerto Ricans: implications for warfarin management in Hispanics. Ethnicity \& disease, 19(4), 390-395. https://www.ncbi.nlm.nih.gov/pubmed/20073138

Flockhart, D. A., O'Kane, D., Williams, M. S., Watson, M. S., Flockhart, D. A., Gage, B., Gandolfi, R., King, R., Lyon, E., Nussbaum, R., O'Kane, D., Schulman, K., Veenstra, D., Williams, M. S., Watson, M. S., \& ACMG Working 
Group on Pharmacogenetic Testing of CYP2C9, VKORC1 Alleles for Warfarin Use (2008). Pharmacogenetic testing of CYP2C9 and VKORC1 alleles for warfarin. Genetics in medicine : official journal of the American College of Medical Genetics, 10(2), 139-150. https://doi.org/10.1097/GIM.0b013e318163c35f

Gaikward, T., Ghosh K, Kulkarni B, Kulkarni V, Ross C. and Shetty S. (2013). Influence of CYP2C9 and VKORC1 gene polymorphism on warfarin dosage, over anticoagulation and other adverse outcomes in Indian Population.European Journal of Pharmacology, 710:80-84. https://www.sciencedirect.com/science/article/abs/ pii/S0014299913002951

Galvez, J. M., Restrepo, C. M., Contreras, N. C., Alvarado, C., Calderón-Ospina, C. A., Peña, N., Cifuentes, R. A., Duarte, D., Laissue, P., \& Fonseca, D. J. (2018). Creating and validating a warfarin pharmacogenetic dosing algorithm for Colombian patients. Pharmacogenomics and personalized medicine, 11, 169-178. https:// doi.org/10.2147/PGPM.S170515

Golwala, H., Jackson, L. R., 2nd, Simon, D. N., Piccini, J. P., Gersh, B., Go, A. S., Hylek, E. M., Kowey, P. R., Mahaffey, K. W., Thomas, L., Fonarow, G. C., Peterson, E. D., Thomas, K. L., \& Outcomes Registry for Better Informed Treatment for Atrial Fibrillation (ORBIT-AF) Registry (2016). Racial/ethnic differences in atrial fibrillation symptoms, treatment patterns, and outcomes: Insights from Outcomes Registry for Better Informed Treatment for Atrial Fibrillation Registry. American heart journal, 174, 29-36. https://doi.org/10.1016/j.ahj.2015.10.028

Guerrero, F. (2009). Farmacogenética de Warfarina. Revista Médica Sanitas, 12(2): 8-12. http:// www.gbcbiotech.com/laboratorio/assets/farmacogenetica-de-warfarina.pdf

Hosseinkhani, Z., Sadeghalvad, M., Norooznezhad, F., Khodarahmi, R., Fazilati, M., Mahnam, A., Fattahi, A., \& Mansouri, K. (2018). The effect of CYP2C9*2, CYP2C9*3, and VKORC1-1639 G>A polymorphism in patients under warfarin therapy in city of Kermanshah. Research in pharmaceutical sciences, 13(4), 377-384. https://doi.org/10.4103/1735-5362.235165

Isaza, C, Henaao, J. y Beltrán, L. (2010). Resistencia y Sensibilidad a Warfarina. Investigaciones ANDINA, 12(20): 100.

Kaye, J. B., Schultz, L. E., Steiner, H. E., Kittles, R. A., Cavallari, L. H., \& Karnes, J. H. (2017). Warfarin Pharmacogenomics in Diverse Populations. Pharmacotherapy, 37(9), 1150-1163. https://doi.org/10.1002/ phar.1982

Li, J., Wang, L., Hu, J., \& Xu, G. (2015). Warfarin use and the risks of stroke and bleeding in hemodialysis patients with atrial fibrillation: A systematic review and a meta-analysis. Nutrition, metabolism, and cardiovascular diseases:NMCD, 25(8), 706-713. https://doi.org/10.1016/j.numecd.2015.03.013

Limdi, N. A., Arnett, D. K., Goldstein, J. A., Beasley, T. M., McGwin, G., Adler, B. K., \& Acton, R. T. (2008). Influence of CYP2C9 and VKORC1 on warfarin dose, anticoagulation attainment and maintenance among EuropeanAmericans and African-Americans. Pharmacogenomics, 9(5), 511-526.

Limdi, N. A., Wadelius, M., Cavallari, L., Eriksson, N., Crawford, D. C., Lee, M. T., Chen, C. H., Motsinger-Reif, A., Sagreiya, H., Liu, N., Wu, A. H., Gage, B. F., Jorgensen, A., Pirmohamed, M., Shin, J. G., Suarez-Kurtz, G., Kimmel, S. E., Johnson, J. A., Klein, T. E., Wagner, M. J., ... International Warfarin Pharmacogenetics Consortium (2010). Warfarin pharmacogenetics: a single VKORC1 polymorphism is predictive of dose across 3 racial groups. Blood, 115(18), 3827-3834.

Liu, N., Irvin, M. R., Zhi, D., Patki, A., Beasley, T. M., Nickerson, D. A., Hill, C. E., Chen, J., Kimmel, S. E., \& Limdi, N. A. (2017). Influence of common and rare genetic variation on warfarin dose among African-Americans and European-Americans using the exome array. Pharmacogenomics, 18(11), 1059-1073. https://doi.org/10.2217/ pgs-2017-0046

Liu, R., Cao, J., Zhang, Q., Shi, X. M., Pan, X. D., \& Dong, R. (2017). Clinical and genetic factors associated with warfarin maintenance dose in northern Chinese patients with mechanical heart valve replacement. Medicine, 96(2), e5658. https://doi.org/10.1097/MD.0000000000005658

Miklosz, J., Kalaska, B., \& Mogielnicki, A. (2018). Pharmacogenetic considerations of anticoagulant medication. Journal of physiology and pharmacology : an official journal of the Polish Physiological Society, 69(4), 10.26402/ jpp.2018.4.01. https://doi.org/10.26402/jpp.2018.4.01 
Miranda, C., Roco, A., Garay, J., Squicciarini, V., Tamayo, E., Agúndez, J., et.al. (2011). Determinación del polimorfismo de CYP2C9*2 y su relación con la farmacocinética de acenocumarol en voluntarios sanos. Revista Chilena de cardiologia, 30, 218-224. https://scielo.conicyt.cl/pdf/rchcardiol/v30n3/art05.pdf

Moyer, T. P., O'Kane, D. J., Baudhuin, L. M., Wiley, C. L., Fortini, A., Fisher, P. K., Dupras, D. M., Chaudhry, R., Thapa, P., Zinsmeister, A. R., \& Heit, J. A. (2009). Warfarin sensitivity genotyping: a review of the literature and summary of patient experience. Mayo Clinic proceedings, 84(12), 1079-1094. https://doi.org/10.4065/ mcp.2009.0278

Natarajan, S., Ponde, C. K., Rajani, R. M., Jijina, F., Gursahani, R., Dhairyawan, P. P., \& Ashavaid, T. F. (2013). Effect of CYP2C9 and VKORC1 genetic variations on warfarin dose requirements in Indian patients. Pharmacological reports: PR, 65(5), 1375-1382. https://doi.org/10.1016/s1734-1140(13)71496-8

Parra, E. J., Botton, M. R., Perini, J. A., Krithika, S., Bourgeois, S., Johnson, T. A., Tsunoda, T., Pirmohamed, M., Wadelius, M., Limdi, N. A., Cavallari, L. H., Burmester, J. K., Rettie, A. E., Klein, T. E., Johnson, J. A., Hutz, M. H., \& Suarez-Kurtz, G. (2015). Genome-wide association study of warfarin maintenance dose in a Brazilian sample. Pharmacogenomics, 16(11), 1253-1263.

Perini, J. A., Vargens, D. D., Santana, I. S., Moriguchi, E. H., Ribeiro-Dos-Santos, A. K., Tsutsumi, M., \& Suarez-Kurtz, G. (2009). Pharmacogenetic polymorphisms in Brazilian-born, first-generation Japanese descendants. Brazilian journal of medical and biological research $=$ Revista brasileira de pesquisas medicas e biologicas, 42(12), 1179-1184.

Raggio V, Neira P, Esperón P, Lorenzo M and Stoll M. (2005). Respuesta terapéutica inadecuada a la warfarina en pacientes genéticamente susceptibles. Revista médica Uruguay, 21:242-246.

Razavi, F. E., Zarban, A., Hajipoor, F., \& Naseri, M. (2017). The allele frequency of CYP2C9 and VKORC1 in the Southern Khorasan population. Research in pharmaceutical sciences, 12(3), 211-221. https:// doi.org/10.4103/1735-5362.207202

Scibona, P., Redal, M. A., Garfi, L. G., Arbelbide, J., Argibay, P. F., \& Belloso, W. H. (2012). Prevalence of CYP2C9 and VKORC1 alleles in the Argentine population and implications for prescribing dosages of anticoagulants. Genetics and molecular research:GMR, 11(1), 70-76. https://doi.org/10.4238/2012.January.9.8

Seng, K., Gin, G., Sangkar, V. and Phipps, E. (2003). Frequency of Cytochrome P450 2C9 (CYP2C9) alleles in three ethnic groups in Malaysia. Asia Pacific Journal of Molecular Biology and biotechnology, 11(2), 83-91.

Shen, A. Y., Yao, J. F., Brar, S. S., Jorgensen, M. B., \& Chen, W. (2007). Racial/ethnic differences in the risk of intracranial hemorrhage among patients with atrial fibrillation. Journal of the American College of Cardiology, 50(4), 309-315. https://doi.org/10.1016/j.jacc.2007.01.098

Tavares, L. C., Marcatto, L. R., Soares, R., Krieger, J. E., Pereira, A. C., \& Santos, P. (2018). Association Between ABCB1 Polymorphism and Stable Warfarin Dose Requirements in Brazilian Patients. Frontiers in pharmacology, 9, 542. https://doi.org/10.3389/fphar.2018.00542

Tsai, C., Marcus, L. Q., Patel, P., \& Battistella, M. (2017). Warfarin Use in Hemodialysis Patients With Atrial Fibrillation: A Systematic Review of Stroke and Bleeding Outcomes. Canadian journal of kidney health and disease, 4, 2054358117735532. https://doi.org/10.1177/2054358117735532

Valentin, I. I., Vazquez, J., Rivera-Miranda, G., Seip, R. L., Velez, M., Kocherla, M., Bogaard, K., Cruz-Gonzalez, I., Cadilla, C. L., Renta, J. Y., Feliu, J. F., Ramos, A. S., Alejandro-Cowan, Y., Gorowski, K., Ruaño, G., \& Duconge, J. (2012). Prediction of warfarin dose reductions in Puerto Rican patients, based on combinatorial CYP2C9 and VKORC1 genotypes. The Annals of pharmacotherapy, 46(2), 208-218. https://doi.org/10.1345/aph.1Q190

Valentín, I. I., Rivera, G., Nieves-Plaza, M., Cruz, I., Renta, J. Y., Cadilla, C. L., Feliu, J. F., Seip, R. L., Ruaño, G., \& Duconge, J. (2014). Pharmacogenetic association study of warfarin safety endpoints in Puerto Ricans. Puerto Rico health sciences journal, 33(3), 97-104. https://pubmed.ncbi.nlm.nih.gov/25244877/

Villagra, D., Duconge, J., Windemuth, A., Cadilla, C. L., Kocherla, M., Gorowski, K., Bogaard, K., Renta, J. Y., Cruz, I. A., Mirabal, S., Seip, R. L., \& Ruaño, G. (2010). CYP2C9 and VKORC1 genotypes in Puerto Ricans: A case for admixture-matching in clinical pharmacogenetic studies. Clinica chimica acta; international journal of clinical chemistry, 411(17-18), 1306-1311. https://doi.org/10.1016/j.cca.2010.05.021 
Villegas-Torres, B., Sánchez-Girón, F., Jaramillo-Villafuerte, K., Soberón, X., \& Gonzalez-Covarrubias, V. (2015). Genotype frequencies of VKORC1 and CYP2C9 in native and Mestizo populations from Mexico, potential impact for coumarin dosing. Gene, 558(2), 235-240. https://doi.org/10.1016/j.gene.2014.12.068

Wattanachai, N., Kaewmoongkun, S., Pussadhamma, B., Makarawate, P., Wongvipaporn, C., Kiatchoosakun, S., Vannaprasaht, S., \& Tassaneeyakul, W. (2017). The impact of non-genetic and genetic factors on a stable warfarin dose in Thai patients. European journal of clinical pharmacology, 73(8), 973-980. https:// doi.org/10.1007/s00228-017-2265-8

Yoon, Y. R., Shon, J. H., Kim, M. K., Lim, Y. C., Lee, H. R., Park, J. Y., Cha, I. J., \& Shin, J. G. (2001). Frequency of cytochrome P450 2C9 mutant alleles in a Korean population. British journal of clinical pharmacology, 51(3), $277-280$.

Zhang, J., Chen, Z., \& Chen, C. (2016). Impact of CYP2C9, VKORC1 and CYP4F2 genetic polymorphisms on maintenance warfarin dosage in Han-Chinese patients: A systematic review and meta-analysis. Meta gene, 9, 197-209. https://doi.org/10.1016/j.mgene.2016.07.002

Zhang, H., Ma, K., Liu, W., Yang, F., Liu, J., \& Zhou, H. (2016). Impact of CYP2C19 gene polymorphism on warfarin maintenance doses in patients with non-valvular atrial fibrillation. Gene, 591(1), 80-84. https:// doi.org/10.1016/j.gene.2016.06.046

\section{Anexo 1}

ANEXO 1

Estadístico de Grubbs de la frecuencia de polimorfismos en el gen CYP2C9

\begin{tabular}{|c|l|l|l|l|l|l|c|c|}
\hline Gen & Variable & $\mathrm{N}$ & \multicolumn{1}{|c|}{ Media } & Desv.Est. & \multicolumn{1}{|c|}{ Mín. } & \multicolumn{1}{c|}{ Máx. } & G & P \\
\hline \multirow{5}{*}{ CYP2C9 } & $1^{*} / 1^{*}$ & 10 & 0.7112 & 0.0892 & 0.5600 & 0.8300 & 1.69 & 0.693 \\
\cline { 2 - 9 } & $1^{*} / 2^{*}$ & 10 & 0.1696 & 0.0517 & 0.0870 & 0.2500 & 1.60 & 0.913 \\
\cline { 2 - 9 } & $1^{*} / 3^{*}$ & 10 & 0.06455 & 0.02969 & 0.00000 & 0.10900 & 2.17 & 0.101 \\
\cline { 2 - 9 } & $2^{*} / 2^{*}$ & 10 & 0.0257 & 0.0387 & 0.0030 & 0.1300 & 2.70 & 0.000 \\
\cline { 2 - 9 } & $2^{*} / 3^{*}$ & 10 & 0.01574 & 0.01861 & 0.00000 & 0.06000 & 2.38 & 0.026 \\
\cline { 2 - 9 } & $3^{*} / 3^{*}$ & 10 & 0.001380 & 0.002463 & 0.000000 & 0.006000 & 1.88 & 0.382 \\
\hline \multirow{2}{*}{$\begin{array}{l}\text { VKORC1- } 1639 \\
\text { AA }\end{array}$} & 7 & 0.1923 & 0.0850 & 0.1260 & 0.3540 & 1.90 & 0.129 \\
\cline { 2 - 9 } & GG & 7 & 0.4997 & 0.0530 & 0.4310 & 0.6000 & 1.89 & 0.137 \\
\cline { 2 - 9 } & 7 & 0.3061 & 0.0860 & 0.1900 & 0.4020 & 1.35 & 1.000 \\
\hline
\end{tabular}

* $\mathrm{P}>0.05$ se acepta la H0, no hay presencia de datos anómalos; $\mathrm{P}<0.05$ se rechaza la H0 hay presencia de datos anómalos. 


\section{Anexo 2.}

ANEXO 2.

Equilibrio de Hardy-Weinberg-valores de $\mathrm{X}^{2}$ calculados

\begin{tabular}{|c|c|c|c|c|c|}
\hline \multirow{3}{*}{$\mathrm{N}^{0}$} & \multirow{3}{*}{ Estudio } & \multirow{3}{*}{ Ubicación } & \multicolumn{3}{|c|}{ X2a } \\
\hline & & & \multicolumn{2}{|c|}{ CYP2C9 } & \multirow{2}{*}{\begin{tabular}{|c|} 
VKORC1 \\
-1639 \\
AA GA \\
GG
\end{tabular}} \\
\hline & & & $\begin{array}{l}{ }^{*} 1 /{ }^{*} 1 \\
{ }^{*} 1 /{ }^{*} 2 \\
* 2 / * 2\end{array}$ & $\begin{array}{l}{ }^{*} 1 /{ }^{* 1} 1 \\
{ }^{*} 1 /{ }^{*} 3 \\
{ }^{*} 3 /{ }^{*} 3\end{array}$ & \\
\hline 1 & $\begin{array}{l}\text { Perini } \\
\text { et.al } \\
(2009)\end{array}$ & $\begin{array}{l}\text { Brasil, } \\
\text { descendencia } \\
\text { mixta }\end{array}$ & $\begin{array}{l}0.11707 \\
<3.84 \mathrm{Se} \\
\text { acepta la } \\
\mathrm{H}_{0}\end{array}$ & $\begin{array}{l}0.2494 \\
<3.84 \\
\text { Se } \\
\text { acepta } \\
\text { la } \mathrm{H}_{0}\end{array}$ & - \\
\hline 2 & $\begin{array}{l}\text { Rodrigues } \\
\text { et.al } \\
\text { (2011) }\end{array}$ & $\begin{array}{l}\text { Brasil, } \\
\text { descendencia } \\
\text { española }\end{array}$ & $\begin{array}{l}1.0137 \\
<3.84 \mathrm{Se} \\
\text { acepta la } \\
\mathrm{H}_{0}\end{array}$ & $\begin{array}{l}0.8546 \\
<3.84 \\
\text { Se } \\
\text { acepta } \\
\text { la } \mathrm{H}_{0}\end{array}$ & $\begin{array}{l}0.0078 \\
<3.84 \mathrm{Se} \\
\text { acepta la } \\
\mathrm{H}_{0}\end{array}$ \\
\hline 3 & $\begin{array}{l}\text { Cifuentes } \\
\text { et.al } \\
\text { (2016) }\end{array}$ & $\begin{array}{l}\text { Colombia, } \\
\text { descendencia } \\
\text { mixta }\end{array}$ & $\begin{array}{l}0.0086 \\
<3.84 \mathrm{Se} \\
\text { acepta la } \\
\mathrm{H}_{0}\end{array}$ & $\begin{array}{l}0.2494 \\
<3.84 \\
\text { Se } \\
\text { acepta } \\
\text { la } \mathrm{H}_{0}\end{array}$ & $\begin{array}{l}1.9233 \\
<3.84 \mathrm{Se} \\
\text { acepta la } \\
\mathrm{H}_{0}\end{array}$ \\
\hline 4 & $\begin{array}{l}\text { Valentin } \\
\text { et.al } \\
\text { (2012) }\end{array}$ & $\begin{array}{l}\text { Puerto Rico, } \\
\text { descendencia } \\
\text { mixta }\end{array}$ & $\begin{array}{l}0.01260 \\
<3.84 \mathrm{Se} \\
\text { acepta la } \\
\mathrm{H}_{0}\end{array}$ & $\begin{array}{l}0.1023 \\
<3.84 \\
\text { Se } \\
\text { acepta } \\
\text { la } \mathrm{H}_{0}\end{array}$ & $\begin{array}{l}0.7526 \\
<3.84 \mathrm{Se} \\
\text { acepta la } \\
\mathrm{H}_{0}\end{array}$ \\
\hline 5 & $\begin{array}{l}\text { Duconge } \\
\text { et.al } \\
\text { (2016) }\end{array}$ & $\begin{array}{l}\text { Puerto Rico, } \\
\text { hispano } \\
\text { caribeños }\end{array}$ & $\begin{array}{l}0.0161 \\
<3.84 \mathrm{Se} \\
\text { acepta la } \\
\mathrm{H}_{0}\end{array}$ & $\begin{array}{l}0.4029 \\
<3.84 \\
\text { Se } \\
\text { acepta } \\
\text { la } \mathrm{H}_{0}\end{array}$ & $\begin{array}{l}0.4107 \\
<3.84 \mathrm{Se} \\
\text { acepta la } \\
\mathrm{H}_{0}\end{array}$ \\
\hline 6 & $\begin{array}{l}\text { Castelan } \\
\text { et.al } \\
\text { (2013) }\end{array}$ & $\begin{array}{l}\text { México, } \\
\text { mestizos }\end{array}$ & $\begin{array}{l}1.3593 \\
<3.84 \text { Se } \\
\text { acepta la } \\
\mathrm{H}_{0}\end{array}$ & $\begin{array}{l}0.3348 \\
<3.84 \\
\text { Se } \\
\text { acepta } \\
\text { la } \mathrm{H}_{0}\end{array}$ & - \\
\hline 7 & $\begin{array}{l}\text { Villegas } \\
\text { et.al } \\
\text { (2015) }\end{array}$ & $\begin{array}{l}\text { México, } \\
\text { mestizos }\end{array}$ & $\begin{array}{l}0.1754 \\
<3.84 \mathrm{Se} \\
\text { acepta la } \\
\mathrm{H}_{0}\end{array}$ & $\begin{array}{l}0.4286 \\
<3.84 \\
\text { Se } \\
\text { acepta } \\
\text { la } \mathrm{H}_{0}\end{array}$ & - \\
\hline 8 & $\begin{array}{l}\text { Benavides } \\
\text { et.al } \\
(2015)\end{array}$ & Chile & $\begin{array}{l}0.02713 \\
<3.84 \mathrm{Se} \\
\text { acepta la } \\
\mathrm{H}_{0}\end{array}$ & $\begin{array}{l}0.8999 \\
<3.84 \\
\text { Se } \\
\text { acepta } \\
\text { la } \mathrm{H}_{0}\end{array}$ & $\begin{array}{l}0.02353 \\
<3.84 \mathrm{Se} \\
\text { acepta la } \\
\mathrm{H}_{0}\end{array}$ \\
\hline 9 & $\begin{array}{l}\text { Miranda } \\
\text { et.al } \\
\text { (2011) }\end{array}$ & Chile & $\begin{array}{l}1.3605 \\
<3.84 \mathrm{Se} \\
\text { acepta la } \\
\mathrm{H}_{0} \\
\end{array}$ & - & - \\
\hline 10 & $\begin{array}{l}\text { Scibonab } \\
\text { et.al } \\
\text { (2012) }\end{array}$ & Argentina & $\begin{array}{l}12.6308 \\
>3.84 \mathrm{Se} \\
\text { rechaza } \\
\text { la } \mathrm{H}_{0}\end{array}$ & $\begin{array}{l}0.1094 \\
<3.84 \\
\text { Se } \\
\text { acepta } \\
\text { la } \mathrm{H}_{0}\end{array}$ & $\begin{array}{l}3.5790> \\
3.84 \mathrm{Se} \\
\text { rechaza } \\
\text { la } \mathrm{H}_{0}\end{array}$ \\
\hline
\end{tabular}


Revista Torreón Universitario, 2021, 10(27), Febrero-Mayo, ISSN: 2410-5708 / 2313-7215

a Se evaluó el valor de $\mathrm{X} 2$ calculado con $\mathrm{X} 2$ tabulado, con un grado de libertad y un nivel de significancia de 0.050 (X2 tab=3.84). Al comparar los valores de X2 calculados con X2 tabulado, se acepta la H0 que indica que la población se encuentra en equilibrio de Hardy-Weinberg, para los estudios de uno a nueve.

b Los valores de X2 obtenidos en este estudio muestran un comportamiento atípico, que se deba posiblemente al tamaño de la muestra. 